\title{
Relato de Experiência em uma Unidade Básica de Saúde de Maceió: a Visão do Usuário Sobre o Direito à Saúde.
}

\author{
Dantas, Lourena Gonçalves; Santo, Karlla Gabrielly Claudino; Anjos, Samila F. \\ dos Santos; Oliveira, Paula Pires de; Cardoso, Saulo Batinga; Almeida, Daniel \\ Ferreira
}

Universidade Federal de Alagoas (Ufal) — lourena13@hotmail.com

Introdução a saúde é um direito fundamental de qualquer cidadão que deve ser garantido pelo Estado, como consta na Constituição Federal de 1988. a organização e o funcionamento da rede de atenção à saúde não são de conhecimento da maioria dos usuários, fato que se reflete nas criticas negativas a assistência da unidade básica de saúde. Conhecer este direito fundamental é essencial para compreensão dos serviços que são ofertados e como eles se articulam na promoção, prevenção e reabilitação da saúde. Metodologia: o objetivo do resumo é relatar a experiência dos alunos do curso de medicina de uma liga acadêmica numa unidade básica de saúde de Maceió, onde foi abordado o tema direito à saúde. a atividade na UBS começou com o grupo se apresentando e mostrando como seria a dinâmica para que os usuários se sentissem à vontade em participar, além de deixar o ambiente mais descontraído. a primeira dinâmica foi baseada no repasse de um objeto, enquanto um membro do grupo ficava de costas. ao comando de "pare", a pessoa que ficava com o objeto era a escolhida. na segunda atividade, duas caixas, uma com 10 figuras sobre hábitos de vida e outra com 10 perguntas sobre direitos à saúde, foram usadas conforme a indicação aleatória das pessoas. Primeiramente, foi utilizada a caixinha com as figuras. Nessa atividade, foram associados cartazes, um com o título "hábitos ruins" e outro com "hábitos bons". a pessoa foi perguntada sobre o que ela achava da figura e onde ela a colaria no cartaz. a cada figura colada, os integrantes da liga contribuiriam mostrando a importância da mudança dos hábitos de vida e incentivando a promoção da saúde. Depois, aconteceu o mesmo método com a outra caixa. Nessa, o grupo lia as perguntas, escutava a opinião deles e depois explicava o tema. Resultados Os usuários presentes participaram ativamente das dinâmicas respondendo as perguntas, expondo suas opiniões e tirando suas dúvidas. Antes de entrar no tema direito à saúde, a atividade sobre estilo de vida saudável apenas constatou que os usuários sabiam muito bem dos hábitos ruins e bons. Já abordando o tema, o conceito de saúde era compreendido pela maioria como o bem-estar geral do indivíduo no âmbito biopsicossocial. em relação aos serviços ofertados, percebeu-se que eles não sabiam como funciona a unidade básica de saúde nem quais os seus principais objetivos que são a promoção da saúde e a prevenção de doenças. Os usuários confundem muito atenção primária com serviços de alta complexidade, a maioria tem a visão de que apena o especialista resolve o problema. a partir das respostas que eram dadas, os membros da liga tiravam as dúvidas e esclareciam os principais direitos do usuário à saúde, mostrando a importância que um líder teria na comunidade para poder cobrar por melhorias. Conclusões Esclarecer as dúvidas desses pacientes pode ajudar na conscientização dos problemas enfrentados e, assim, favorecer positivamente no entendimento de como se organiza e funciona a rede de serviços de saúde, principalmente a atenção primária.

Dantas, Lourena Gonçalves; Santo, Karlla Gabrielly Claudino; Anjos, Samila F. dos Santos; Oliveira, Paula Pires de; Cardoso, Saulo Batinga; Almeida, Daniel Ferreira. Relato de Experiência em uma Unidade Básica de Saúde de Maceió: a Visão do Usuário Sobre o Direito À Saúde.. In: Anais do Congresso Internacional de Humanidades \& Humanização em Saúde [= Blucher Medical Proceedings, num.2, vol.1]. São Paulo: Editora Blucher, 2014. ISSN 2357-7282

DOI 10.5151/medpro-cihhs-10615 